\title{
La representación fotográfica en el estudio de las ciudades guerrerenses $1930-1980$
}

\author{
The Photographic Representation and the Study of the Cities in Guerrero
}

1930-1980

\section{Representação fotográfica no estudo das cidades de Guerrero 1930-1980}

\section{Esperanza Hernández Árciga}

Universidad Autónoma de Guerrero, Centro de Investigación y Posgrado en Estudios

Socioterritoriales, México

esperanzaarciga@uagro.mx

https://orcid.org/0000-0001-9705-5662

\section{Resumen}

Desde sus inicios, la fotografía ha estado relacionada con la ciudad. Las imágenes inspiradas por los elementos urbanos son variadas: desde paisajes urbanos, fotografía de arquitectura y foto de calle hasta registros técnicos de obras de urbanización. Dichas imágenes, en gran parte de los casos, se usaron con fines de difusión, por lo que fueron puestas en circulación a través de diversos medios. Ese fue el caso de las imágenes que acompañaron el proceso de impulso y consolidación de Acapulco como destino turístico. El punto de partida fue la consideración de que para comprender el discurso fotográfico es necesario entender su relación con el contexto histórico-cultural del que surgió. Por lo que se analizaron las imágenes generadas para su promoción durante la trayectoria turística de Acapulco, y el proceso de expansión, considerando la organización territorial del puerto en términos de su vocación turística y la relación con otras ciudades, especialmente con Chilpancingo, capital del estado de Guerrero. Este artículo es parte del proyecto "La ciudad representada. Fotografía urbana en Guerrero", cuyo propósito es analizar las representaciones visuales de las ciudades guerrerenses. Por las diferencias en la temporalidad en que ocurren las 


\section{Revista Iberoamericana \\ de las Ciencias Sociales y \\ Humanísticas}

ISSN: 2395 - 7972

transformaciones de una y otra ciudad, se consideraron fotografías producidas en las décadas de los 30 hasta los 70, para la ciudad Acapulco; y entre los años 50 hasta los 80 para Chilpancingo. Solo se consideraron aquellas imágenes que han sido incorporadas en libros académicos, de arte o promoción. La intención del artículo es proponer la fotografía como fuente fundamental en los estudios urbanos, y mostrar, a la vez, la importancia de documentarla adecuadamente.

Palabras clave: Acapulco, Chilpancingo, fotografía urbana, representación visual, tarjeta postal.

\section{Abstract}

Since its very beginnings the photography and the city have been related. Urban landscapes, architectural photography, street photography and timely records urbanization processes, they are images that inspired the elements of the urban space. Such images were used, mostly, to be spread, so they were placed in the social media channels. The case of Acapulco images accompanied the process of its momentum and consolidation as tourist destination. The starting point was the consideration that it is necessary to understand the cultural-historical context in which the photographic speech was enrolled. We analyzed the images generated for Acapulco promotion during its tourist trajectory and expansion process, considering the port territorial organization, in terms of its tourist vocation and the relationship with other cities, especially with the state capital of Chilpancingo. This paper is part of the project The represented city. Urban photography in Guerrero, its purpose was to analyze the visual representations of the cities in Guerrero between the 30's and 70's for Acapulco, and 50's and 80's for Chilpancingo. We only took those images that have been incorporated into academic, art or promotion books. And its intent is to recommend the photography as a fundamental source in urban studies, showing the importance of document it properly.

Keywords: Acapulco, Chilpancingo, urban photography, visual representation, postcard. 


\section{Revista Iberoamericana \\ de las Ciencias Sociales y \\ Humanísticas}

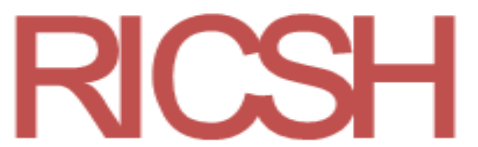

ISSN: 2395 - 7972

\section{Resumo}

Desde a sua criação, a fotografia tem sido relacionada à cidade. As imagens inspiradas em elementos urbanos são variadas: de paisagens urbanas, fotografia arquitetônica e fotografia de rua a registros técnicos de obras de urbanização. As referidas imagens, em grande parte dos casos, foram usadas para fins de transmissão e, por isso, circularam por vários meios de comunicação. Foi o caso das imagens que acompanharam o processo de promoção e consolidação de Acapulco como destino turístico. O ponto de partida foi a consideração de que, para entender o discurso fotográfico, é necessário entender sua relação com o contexto histórico-cultural do qual emergiu. Para tanto, foram analisadas as imagens geradas para sua promoção durante a carreira turística de Acapulco e o processo de expansão, considerando a organização territorial do porto em termos de vocação turística e o relacionamento com outras cidades, principalmente com Chilpancingo, capital do estado. de guerreiro. Este artigo faz parte do projeto "A cidade representada. Fotografia urbana em Guerrero ", cujo objetivo é analisar as representações visuais das cidades de Guerrero. Devido às diferenças de temporalidade em que ocorrem as transformações de uma cidade e de outra, foram consideradas fotografias produzidas nas décadas de 30 a 70 para a cidade de Acapulco; e entre os anos 50 e 80 para Chilpancingo. Somente foram consideradas as imagens incorporadas em livros acadêmicos, de arte ou promocionais. A intenção do artigo é propor a fotografia como fonte fundamental nos estudos urbanos e, ao mesmo tempo, mostrar a importância de documentá-la adequadamente.

Palavras-chave: Acapulco, Chilpancingo, fotografia urbana, representação visual, cartão postal.

Fecha Recepción: Diciembre 2019

Fecha Aceptación: Mayo 2020 


\section{Revista Iberoamericana \\ de las Ciencias Sociales y \\ Humanísticas}

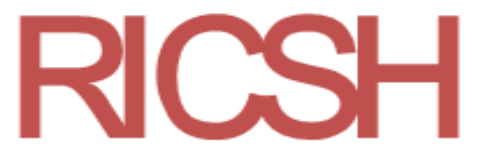

ISSN: $2395-7972$

\section{Introducción}

En este artículo se presentan avances de la investigación en curso "La ciudad representada. Fotografía urbana en Guerrero", 1 cuyo objetivo es analizar las representaciones visuales de las ciudades guerrerenses a través de sus fotografías, especialmente aquellas que se ponen en circulación con el propósito de difundir la imagen urbana. Entre las imágenes estudiadas se consideran las tarjetas postales, las imágenes técnicas tomadas con fines de registro de obras urbanas y la fotografía de prensa. Estas imágenes fueron incorporadas en otros medios impresos (libros, folletos, etc.) con la finalidad de difundir los logros del Gobierno. En este caso particular, reseño los libros donde la fotografía es la protagonista. Una parte de ellos, como se muestra más adelante, fueron publicados por el Gobierno del estado de Guerrero, y distribuidos por instituciones gubernamentales para fines publicitarios o educativos, según se menciona en algunos. Otra parte son trabajos académicos de historia $\mathrm{y}$ arquitectura.

El período seleccionado para la investigación abarca desde 1930 hasta la década de $\operatorname{los} 70^{2}$ para Acapulco, y entre los años 50 y 80 en el caso de Chilpancingo. La razón de este recorte es debido a que se intenta mostrar la paradoja de este proceso: la carretera MéxicoAcapulco se anunció como una oportunidad que resolvería la pobreza e impulsaría el desarrollo de la entidad; 40 años después, sin embargo, con el surgimiento de la guerrilla y la violencia de la llamada guerra sucia, hubo una agudización evidente de las contradicciones económicas: en realidad tan solo unos pocos se beneficiaron del auge logrado en los años previos y la gran mayoría de la población sufrió de empobrecimiento.

Esta no es la única lupa con la que se pretende analizar las imágenes de Guerrero. Interesa de manera especial ubicarlas a la luz del desarrollo urbano, que implica tanto las tendencias de su expansión y crecimiento como las transformaciones generadas a partir de la actividad económica prioritaria. En ese sentido, se consideraron las dos principales ciudades ubicadas en el circuito de esta dinámica, Acapulco y Chilpancingo, las cuales, por lo mismo, vivieron un proceso de urbanización muy violento, en función del papel que jugaron en el desarrollo de la actividad turística, y cuya fisonomía tuvo cambios muy drásticos, al grado

\footnotetext{
1 Desarrollada durante una estancia académica en el Instituto Mora, institución a la que agradezco su hospitalidad, en particular a la Dra. Regina Hernández Franyuti y al Dr. Alberto del Castillo Troncoso

2 Periodo que parte de la apertura de la carretera México-Acapulco y el inicio de la actividad turística en el estado a la década en la que algunos autores (Garibay, 1978; Ramírez, 1987) ubican el periodo de declive de dicha actividad, debido a factores de violencia y de contaminación de la bahía.
} 


\section{Revista Iberoamericana \\ de las Ciencias Sociales y \\ Humanísticas}

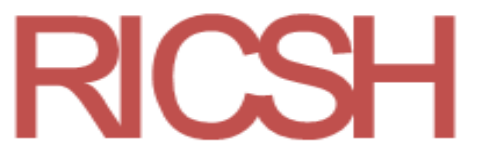

ISSN: 2395 - 7972

que, aseguran Babini, Alcaraz, Hernández y Salgado (2009), son las dos ciudades con mayores pérdidas en patrimonio arquitectónico. Sin duda se trata de una situación que, por sí sola, permite considerar el gran valor documental que la mirada fotográfica aporta en el estudio sobre el desarrollo urbano de Guerrero.

Por lo que se parte de la consideración que la investigación urbana se puede enriquecer con el estudio de las representaciones visuales de la ciudad. De esta manera, la intención del presente artículo es mostrar a los estudiosos urbanos que la fotografía puede aportar información. A la vez, se espera incidir en autores que ya incorporan fotografías en sus estudios sobre la importancia de documentarlas adecuadamente, proporcionando las coordenadas básicas: fecha, lugar y autoría.

Se revisaron siete libros y dos folletos, de los cuales cuatro son de Acapulco y cinco de Chilpancingo. En el primer caso, se trata del libro del escritor Francisco Tario con fotos de Lola Álvarez Bravo (1993), y tres textos académicos de arquitectura (Alcaraz 2007; 2009; y Fares 2010). En el segundo caso, un libro sobre el movimiento social de 1960 con fotografías de Jesús Salmerón (1991), el libro de Blanca Jiménez y Samuel Villela (1998) sobre la familia Salmerón, un texto de la historia de Chilpancingo (Gutiérrez y Rodríguez, 1987) y dos folletos producidos por el Gobierno del estado de Guerrero.

\section{Materiales y métodos}

La fotografía se hizo presente en la vida social desde sus primeros años de existencia. En las interacciones personales a través de las tarjetas de visita y las tarjetas postales, que lo mismo difundían las vistas de ciudades que las fotografías de personajes del teatro o los llamados tipos populares, con personajes del pueblo. Muy pronto su uso se introdujo a otros ámbitos como la prensa, la publicidad, las fichas policiales u otros tipos de registro. Así hasta llegar a la actualidad, en que las imágenes dominan la comunicación a través de los medios y las redes sociales.

Sin embargo, los estudios sociales vistos desde la producción de imágenes, o los que consideran a la fotografía como una fuente de información o un recurso metodológico, son sumamente recientes. En nuestro país, el primer acercamiento de ese tipo se sitúa en 1980 con el libro de Claudia Canales (1980) sobre el fotógrafo Romualdo García. El método utilizado por la autora implicó situar al personaje estudiado y su producción en el contexto social que le tocó vivir, de una manera crítica. Este método es una constante en otros estudios 


\section{Revista Iberoamericana \\ de las Ciencias Sociales y \\ Humanísticas}

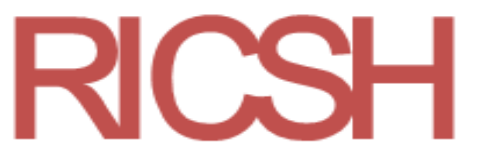

ISSN: 2395 - 7972

fotográficos porque es un acercamiento adecuado a la comprensión y lectura de las imágenes fotográficas, debido a que no solo aborda el contexto histórico social de una época determinada, sino que también considera la cultura visual de esta.

Para enriquecer el método histórico, el estudio se complementa con un análisis iconográfico e iconológico, debido que se trata de documentos visuales construidos conforme a reglas artísticas de composición. No obstante, puesto que en su construcción se involucra la cámara, la cual introduce elementos que no siempre guardan semejanza con el referente, no todas las propuestas provenientes de la historia del arte son adecuadas. En ese sentido, se retoma la propuesta de Boris Kossoy (2014), ya que se considera mucho más apropiada para analizar fotografías que no solo tienen un sentido estético, sino también un propósito político, económico o social.

En dicha propuesta, Kossoy (2014) plantea que el análisis iconográfico es “como la arqueología" de la fotografía y sirve para documentar lo más posible los datos de su producción, incluyendo las condiciones materiales, así como el "inventario de informaciones codificadas" que contiene la imagen (p. 179). El iconológico, por su cuenta, parte de la consideración de que el asunto fotografiado es una representación. Si bien tiene una relación con el referente real, prevalece el hecho de que es una construcción, la cual corresponde a una "manera de ver y comprender" (p. 179), un punto de vista particular del mundo. Por lo tanto, en este punto de la fase interpretativa, se ingresa a la dimensión de las mentalidades y el análisis de la cultura visual de una época en general, y del autor en particular.

En el caso que se estudia, esta forma de acercarse al tema es muy pertinente porque permite comprender el contexto de la producción de las vistas urbanas y su naturaleza. Pues se trata de imágenes que rápidamente tomaron un lugar principal en la producción de los primeros fotógrafos, ya que constituían una manera de difundir el nuevo invento entre los curiosos que se arremolinaban a observar, y al mismo tiempo, tenían un uso comercial importante, debido al hecho de que muy pronto se convirtieron en objetos de colección y en regalos obligados de quienes viajaban, para enviar a la familia y amistades. No obstante, más allá de la romantización, se debe considerar que su producción obedece fundamentalmente a necesidades publicitarias, por lo que son fotografías construidas con la intención de atraer visitantes. "Las postales no son documentos neutrales ni científicos, pero como la cultura y la historia se 'construyen' para ser consumidas y, por tanto, constituyen ficciones de complicada fabricación" (Burian, 1999, p. 46). 


\section{Revista Iberoamericana \\ de las Ciencias Sociales y \\ Humanísticas}

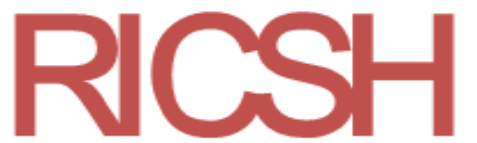

ISSN: 2395 - 7972

El aviso es importante para entender con qué tipo de imágenes se trabaja, pues el mismo autor advierte que, si bien tienen un valor histórico, también puede suceder que muestren "un mundo que jamás existió" (Burian, 1999, p. 46). Por otro lado, en su libro sobre la construcción de imaginarios en la arquitectura mexicana, Catherine Ettinger (2017) recurre a este tipo de fuentes situándolas en el contexto de las tendencias en la arquitectura y en uno más amplio, histórico y social, que permite entender la aparición de nuevos tipos de edificaciones en el paisaje urbano, como las gasolineras, y otras relacionadas con la movilidad de los turistas.

Además de las postales, también se debe comprender la producción de la fotografía de arquitectura. ${ }^{3}$ De acuerdo con Laura González (2010), no se trata del retrato de un motivo únicamente, sino de un concepto, en el sentido de que la producción de imágenes de los hechos arquitectónicos varía según la evolución de estos. De esta forma, la autora expone cómo, a partir de la aparición de nuevos estilos, se generan acercamientos fotográficos diversos que están relacionados claramente entre sí.

Otras imágenes incorporadas en los libros analizados provienen del fotoperiodismo. Para su análisis es necesario hacer una distinción también entre la fotografía documental, cuyo interés es denunciar o dar a conocer problemas sociales, de la fotografía de prensa, ${ }^{4}$ la cual, en algunos casos, tenía el encargo de difundir las acciones de las autoridades como estrategia política. Estas se generaban a partir del control de la prensa o del pago por sus servicios.

Finalmente, para contextualizar las fotografías, en términos de la trayectoria territorial y de crecimiento urbano, entre las fuentes consultadas fue fundamental para el análisis la fotografía aérea de ambas ciudades. La vista a vuelo de pájaro fue muy importante para la planeación urbana y el reordenamiento territorial. La compañía Aerofoto ${ }^{5}$ comercializó imágenes verticales a inmobiliarias, constructores y planeadores urbanos desde la década de los 30. Acapulco fue uno de los sitios fotografiados con dichos fines desde la temprana aparición de este tipo de fotografía. Este hecho convierte a la fotografía aérea en un documento de primera mano en el estudio de las transformaciones del territorio:

\footnotetext{
${ }^{3}$ Es importante distinguir entre foto de arquitectura y las fotos técnicas, necesariamente descriptivas, que ingenieros y arquitectos usan en los espacios de proyección y durante los procesos de construcción o de obra pública. Y que pasado el tiempo también se difunden con otros fines.

${ }^{4}$ Rebeca Monroy (2015) sitúa la diferencia de la siguiente manera: la fotografía documental es un trabajo independiente y la de prensa se realiza bajo las órdenes de un medio periodístico.

5 Acervo custodiado actualmente por la Fundación ICA.
} 


\section{Revista Iberoamericana \\ de las Ciencias Sociales y \\ Humanísticas}

ISSN: $2395-7972$

El avión es una especie de atlas en acción. Su movimiento sobre el paisaje permite apreciar con la mirada las formas territoriales y los límites de estas formas, las discontinuidades espaciales, los usos diferenciados del espacio que se yuxtaponen en el mundo (Besse, 2003, p. 353).

Distinguir todas estas imágenes, diferentes entre sí por las condiciones de su producción en términos de las intenciones, y por lo mismo, por sus recursos técnicos y de composición, que responden a esos objetivos, es fundamental. Para los fines de la investigación, la distinción resulta imprescindible, pues comprender las circunstancias de producción de cada imagen permite tener elementos sólidos para su análisis.

En resumen, contextualizar la foto debidamente implica, además de identificar sus coordenadas básicas (tiempo, espacio, autoría), que se reconozca y reflexione sobre las retóricas de cada época, la estética que se imponía, las influencias de las fotografías de viaje, de las postales y otros usos hegemónicos que cada época imprimió en la producción de imágenes. De otra manera, no comprenderíamos por qué ciertas zonas de las ciudades, las menos, fueron capturadas desde diversos ángulos, perspectivas y en distintos momentos, mientras que grandes áreas urbanas permanecieron a oscuras. Y si fueron retratadas, lo fue con un fin distinto.

Para concluir este apartado, se recalca que, si bien hay más libros que pudieron ser incluidos, se seleccionaron solo siete libros y dos folletos, de los cuales, como ya se mencionó, cuatro son de Acapulco y cinco de Chilpancingo: el libro de Tario con fotos de Lola Álvarez Bravo (1993) y tres textos académicos de arquitectura; un libro sobre el movimiento social de 1960 (Salmerón, 1991), el libro de Blanca Jiménez y Samuel Villela sobre la familia Salmerón (1998), un texto de la historia de Chilpancingo (Gutiérrez y Rodríguez, 1987) y dos folletos producidos por el Gobierno del estado, respectivamente. Los criterios de selección responden al hecho de que incluyen imágenes de ambas ciudades durante distintos momentos de su proceso de expansión urbana. 


\section{Revista Iberoamericana \\ de las Ciencias Sociales y \\ Humanísticas}

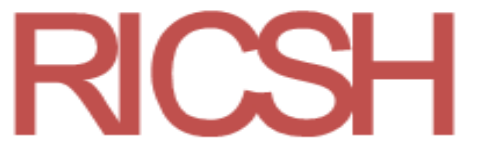

ISSN: $2395-7972$

\section{Resultados}

En un artículo publicado en 1988, Carlos Illades presenta una bibliografía comentada de texto básicos sobre el estado guerrerense. Agrupada en 13 temas, destacan los libros sobre la historia de la entidad (incluye, también, títulos de geografía, antropología, literatura, entre otros). Antes que nada, Illades (1988) no deja pasar la oportunidad de señalar lo paradójico de la poca cantidad de textos que abordan los hechos sucedidos en Guerrero en comparación con otros estados, a pesar de la gran participación que la población guerrerense ha tenido en hechos históricos nacionales y a pesar de su localización geográfica, tan cercana al centro del país.

La bibliografía detallada que presenta el investigador es el resultado de la consulta en 12 bibliotecas. Y si bien se trata de una relación muy completa, llama la atención la ausencia del libro Acapulco en la historia y la leyenda de Vito Alessio Robles de 1932, que para los fines de este trabajo fue importante no solo por su contenido, sino también como evidencia del interés que suscitó Acapulco, en particular, y Guerrero en general, a raíz de la apertura de la carretera México-Acapulco, dado que el autor así lo explicita (objetivo que se refuerza al iniciar el texto con la imagen del primer plan urbano de la ciudad de Acapulco del arquitecto Carlos Contreras elaborado en 1931 para la Secretaría de Comunicaciones y Obras Públicas). Carlos Illades (1988) tampoco incluye el libro de Francisco Tario con fotos de Lola Álvarez Bravo (1993); sí, en cambio, el libro monográfico de Angélica Gutiérrez y Héctor Rodríguez (1987), pero solo aludiendo al texto y a la información que contiene, no a las fotografías.

Estas ausencias, y el hecho de que han salido nuevos libros con información gráfica después de la publicación de ese artículo, fueron un impulso para contribuir con un nuevo capítulo al esfuerzo de inventariar textos que abonen al estudio social del estado. En el caso particular, dirigiendo la mirada a los textos que incorporan imágenes, y que nos permite repensarlas como documentos sociales susceptibles de ser usados como fuentes de información. 


\section{Revista Iberoamericana \\ de las Ciencias Sociales y \\ Humanísticas}

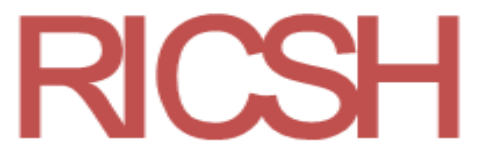

ISSN: 2395 - 7972

\section{Acapulco}

El 11 de noviembre de 1927 es inaugurada la carretera México-Acapulco, aunque quedaría terminada hasta 1933. Este hecho es señalado en otros estudios (Ramírez, 1987; Valenzuela y Coll, 2010) como un factor primordial para la entidad, pues si bien había tenido un rol importante en los siglos anteriores como puerto comercial, las fuentes coinciden en señalar que las operaciones comerciales con el centro del país se habían suspendido y la región había quedado aislada en la época posterior a la Independencia.

Ramírez (1987) ubica entre 1927-1954 el despegue de la actividad turística con la construcción de infraestructura adecuada: hoteles, avenidas, pista de aterrizaje y gasolineras, lo que impulsa también cambios importantes en el crecimiento de la ciudad y de su paisaje. Por su parte, Valenzuela y Coll (2010) enfatizan más en las características del proceso que vivió la ciudad y sus habitantes al dividir esta etapa en dos momentos. Uno relativo al enlace terrestre y al proceso de expropiaciones para lograr la ampliación del territorio destinado al turismo (señalan que desde 1928 se inició con las expropiaciones a los ejidos para beneficio privado). Un segundo momento, de 1946 a 1952, lo relacionan con su proyección como destino internacional, donde el cine de Hollywood y el mexicano jugaron un papel muy importante.

A este periodo, la autora Ettinger (2017) lo llama "de motoristas", pues está relacionado con la adecuación de las ciudades y las carreteras para el uso del automóvil. De esta manera, la expansión urbana de Acapulco inicia con la edificación de hoteles en Península de las Playas, pero muy pronto se construyen otros en diferentes puntos de la bahía: la avenida costera inaugurada en 1949 y fotografiada por Lola Álvarez Bravo se inscribe en esta estrategia.

Un segundo periodo es su consolidación, que los autores de ambos textos sitúan en la década de los 70. Pues de ahí en adelante consideran que la violencia, los problemas urbanos y la contaminación de la bahía, entre otros factores, colocan al puerto en una situación de crisis. Las imágenes incluidas en los libros revisados permiten observar los cambios del paisaje urbano en los años estudiados. 


\section{Revista Iberoamericana \\ de las Ciencias Sociales y \\ Humanísticas}

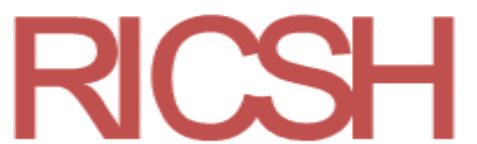

ISSN: $2395-7972$

\section{Un libro fotográfico: Acapulco en el sueño (1993) ${ }^{6}$}

Entre 1949 y 1950, Lola Álvarez Bravo fotografía Acapulco en pleno auge turístico. Las fotografías son acompañadas con fragmentos aforísticos, escritos por Francisco Tario, los cuales son "deliberadamente fotográficos, quieren reproducir por escrito lo instantáneo de la fotografia, lo conmovedoramente inmediato de la imagen sin tiempo" (Espinasa, 2000). La información que circula en la Red, acerca del proceso de registro de imágenes para el libro, muestra a Tario acompañando a la fotógrafa. Pese a ello, se le da el crédito del libro al escritor, y solo se menciona "con fotografías de Lola Álvarez Bravo", lo que sugiere que son las fotos las que acompañan al texto, y no que ambos expresan desde diferentes ámbitos el ensueño acapulqueño. La razón quizás estriba en que la misma fotógrafa se distanciaba de este trabajo porque se trataba de una tarea inusual para ella, pues las imágenes solicitadas se acercaban mucho a la fotografía de publicidad (Hernández, 2017).

Dentro de las imágenes, que en su gran mayoría corresponden al mar y su entorno, se destacan tres grandes planos generales de la ciudad de Acapulco (Figura 1). Estas imágenes no van acompañadas de texto alguno, quizás porque están colocadas a dos páginas. Dos de ellas tienen perspectivas muy similares: la estación marítima aparece enfocada a la derecha de la foto y la zona central de la ciudad en el lado opuesto, donde destacan los edificios de los hoteles de la época. En una imagen se muestra a la ciudad con un gran contraste de sombras, efecto que produce el atardecer: mientras los edificios blancos resplandecen con la luz, las sombras oscurecen el paisaje. La otra es una escena nocturna. El encuadre de esta permite ver, a través de la línea de luz de las lámparas de la calle, la traza de la costera recién inaugurada. ${ }^{7}$ Los haces de luz trazados por los pocos autos que circulaban también hacen lo propio.

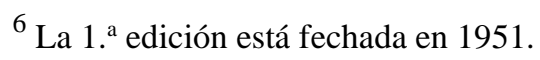

${ }^{7}$ El 28 de febrero de 1949 por Miguel Alemán Valdez.
} 


\section{Revista Iberoamericana \\ de las Ciencias Sociales y \\ Humanísticas}

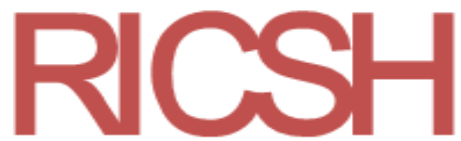

ISSN: 2395 - 7972

Figura 1. Tres grandes planos generales de la ciudad de Acapulco
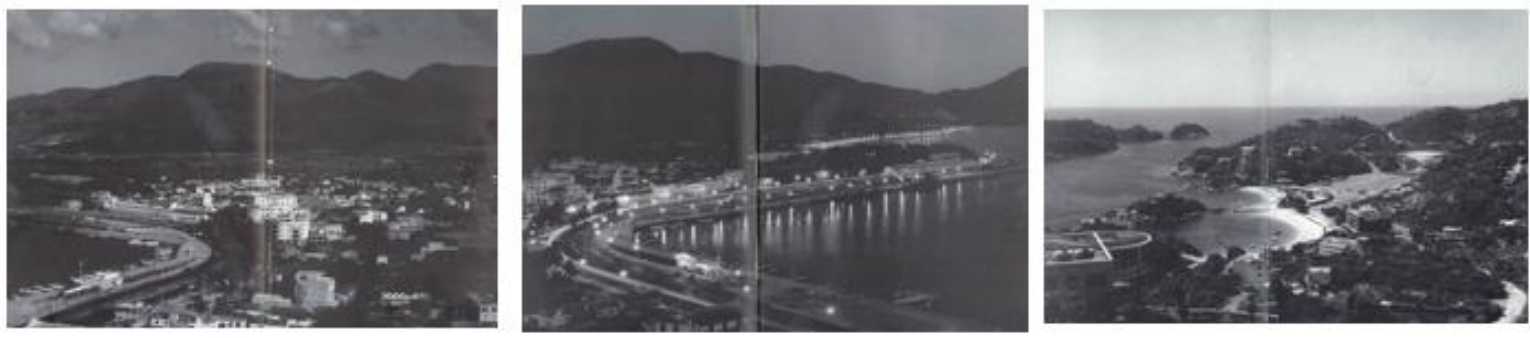

Fuente: Tario y Álvarez (1993)

Una tercera imagen enfoca a la bahía en la zona de Caleta. Se observa con toda nitidez las vías trazadas para recorrer la Península de las Playas, que comienza a desarrollarse desde la temprana época de la actividad turística. Lo que las imágenes muestran, sin ser su propósito, es un aspecto de la urbanización del puerto en ese momento, donde el crecimiento de la vialidad con el motivo de explotar diferentes lugares de la bahía era una de las acciones prioritarias en esos años.

Al final del texto, Tario hace un recuento de los lugares que conforman Acapulco, y contabiliza tres puntas, tres lagunas, veinte playas y treinta y un barrios, que dan cuenta, si se apoya en otros documentos, cartográficos quizás, de la extensión territorial urbana en ese momento.

El texto citado es un facsímil de la primera edición, publicada en 1993 por Fundación Televisa. Entre la edición original y la citada hay 10 fotografías que tuvieron que ser sustituidas porque los negativos se habían perdido. De los libros que se reseñan aquí, este es el que tuvo un mayor tiraje, pues de la primera edición se imprimieron 7000 ejemplares y 20000 de la segunda.

\section{Tres textos sobre arquitectura de Acapulco}

Laura González (2010) asegura que la relación fotografía-arquitectura ha sido siempre muy estrecha. Quizá se deba a ello que los textos de arquitectura vayan siempre acompañados de fotografías. No obstante, eso no garantiza que a estas se les dé un tratamiento adecuado. Pero sí sucede, como veremos a continuación, que las imágenes seleccionadas para estos estudios suelen abarcar un amplio rango, pues, tal y como dice González (2010), la foto de arquitectura fue generando soluciones creativas a medida que la tecnología mejoraba y la ciudad incorporaba nuevas formas arquitectónicas y urbanísticas (p. 93). 


\section{Revista Iberoamericana \\ de las Ciencias Sociales y \\ Humanísticas}

ISSN: $2395-7972$

En este apartado, la selección incluye tres textos académicos sobre arquitectura en Acapulco: dos de ellos abordan la arquitectura de los hoteles (Osbelia Alcaraz, 2007, 2009) y el otro trata sobre la historia de la arquitectura en la entidad (Fares, 2010).

Cabe señalar que, aunque los tres libros incorporan muchas imágenes, tanto antiguas como recientes, no proporcionan los datos de estas. En algunos casos, las fichas mencionan la fecha, una descripción escueta del lugar donde fue tomada la imagen, o la autoría. Pero no hay una regla constante en cada ficha o pie de foto que acompaña a la imagen, sobre todo en los libros de la autora Osbelia Alcaraz (2007, 2009).

El libro de Fares (2010) ostenta un gran acopio de fotografías que abarcan un amplio periodo. Algunas son series que muestran al objeto arquitectónico desde varios puntos de vista. Así, algunos edificios podemos observarlos en su contexto, aislados o en detalle, y con perspectivas de picada o contrapicada. Como ya se mencionó líneas arriba, si en el caso de Alcaraz $(2007,2009)$ el estudio se enfoca solamente en la arquitectura hotelera, el estudio de Fares amplía su rango al incorporar viviendas particulares, la arquitectura religiosa, deportiva, comercial, gubernamental e, igualmente, los hoteles que se han hecho en el puerto en diferentes épocas.

Lamentablemente, Fares (2010) no hizo un trabajo de análisis de la fotografía, porque con un acopio tan importante pudo haber enriquecido el trabajo con mejores y mayores datos acerca de los edificios estudiados. Al final del texto, sin embargo, sí proporciona una pista, pues enlista a las personas que le proporcionaron las imágenes; en algunos casos se trata de colecciones de los mismos arquitectos.

\section{Chilpancingo}

El crecimiento de la ciudad se produjo a raíz de su papel como ciudad capital, pero también debido a que está situada a la orilla de la carretera México-Acapulco. Cabe recordar que el contexto es el de la consolidación del puerto como destino turístico. La fotografía aérea de 1951 de Chilpancingo muestra que su morfología era cuadrada y las dimensiones todavía eran semejantes entre sus cuatro costados. En ese año, la corriente de turistas aún se movía por las calles centrales. Su límite al poniente era el río Huacapa.

En 1955 se construye un libramiento, por lo que el flujo de turistas se desplaza por fuera de la ciudad. Igualmente, su expansión comienza a alargarse en paralelo con la carretera. En la fotografía aérea de 1961 ya se visualizan áreas separadas de la ciudad, 


\section{Revista Iberoamericana \\ de las Ciencias Sociales y \\ Humanísticas}

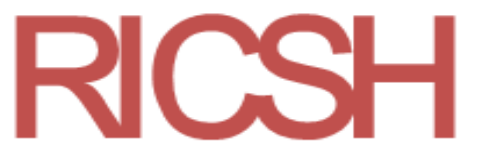

ISSN: 2395 - 7972

aglutinadas junto a la carretera. Pese a ello, el Huacapa continúa siendo un margen duro. Pero es hasta 1971 cuando se evidencia más claramente esa tendencia. Surgen nuevos asentamientos, tanto para el sur y norte como al poniente, del otro lado de la carretera. El establecimiento de desarrollos urbanos fue impulsado por la política de Rubén Figueroa, cuya intención era desplazar del centro de la ciudad los centros comerciales tradicionales y las oficinas administrativas.

En Chilpancingo se presentan dos lógicas de crecimiento, las cuales se pueden observar en dos diferentes superficies urbanas. Un primer crecimiento, por contigüidad, se observa en el eje norte-sur. Crecimiento que no solo se debe al trazo de la carretera, sino también a la forma del valle, y al hecho de que toda esta zona está asentada sobre la parte más baja y plana de este.

La otra dimensión, en la que se evidencia con mayor claridad el crecimiento a través del sistema viario, son las colonias establecidas sobre los cerros que rodean al valle, tanto hacia el oriente como al poniente. El procedimiento de los asentamientos en estos casos ha sido la apertura de brechas hacia zonas en condiciones habitables. De modo que si se voltea a ver, desde las partes bajas hacia los cerros, lo que se observa es una gran cantidad de caminos con cruzamientos por todas partes.

En lo relativo a la fisonomía urbana, esta empieza a cambiar desde la introducción de la carretera, pues aparecen en el paisaje elementos que no existían antes, como las gasolineras; algunas de ellas dispuestas en espacios públicos populares. Y algunas casas se convierten en hoteles y restaurantes. Las imágenes incluidas en los textos que se comentan a continuación se producen entre los años 40 y 60 .

\section{El movimiento social de 1960: 1960: Historia gráfica de un movimiento social (1991)}

El año de 1960 fue muy importante en la historia de la ciudad de Chilpancingo y del estado de Guerrero. En 1957 había tomado posesión el Gral. Raúl Caballero Aburto como gobernador del Estado ante la inconformidad de la gente. En ese mismo año, un temblor, cuyo epicentro se localizó en el municipio de Chilpancingo, causó graves destrozos en la región centro de Guerrero. Este hecho aceleró los cambios urbanísticos que ya experimentaba la ciudad desde los años 50 en su fisonomía, pues viviendas edificadas con arquitectura vernácula fueron sustituidas por otro tipo de construcciones. 


\section{Revista Iberoamericana \\ de las Ciencias Sociales y \\ Humanísticas}

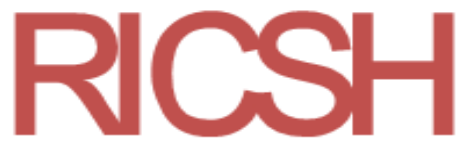

ISSN: $2395-7972$

La inconformidad resultante se canalizó en un movimiento universitario, al que pronto se sumaron otros sectores de la sociedad en apoyo a los estudiantes. El texto de esta sección muestra una parte importante de las imágenes difundidas en la prensa a nivel nacional durante dicho momento de efervescencia.

El libro de imágenes de Jesús Salmerón (1991) fue publicado luego de 30 años de ocurrido el movimiento por la autonomía universitaria de 1960. Está dividido en dos partes: en una primera se exponen testimonios de participantes y estudiosos del movimiento; en la segunda se presentan 101 fotos del suceso. Ambas partes están separadas, pues los textos no hacen mención de las imágenes, y en la cronología de los sucesos las fechas mencionadas en unas y otras no se corresponden. La selección de las fotografías no es muy atinada, pues si bien se intenta seguir una secuencia de los hechos hay algunas imágenes que no muestran lo que el pie de foto indica sobre los momentos clave del movimiento.

Puesto que una gran parte de los sucesos del movimiento ocurren en las calles, la mayoría de las imágenes son vistas de espacios públicos, en donde, si bien el foco está puesto en la muchedumbre, en los detalles se pueden observar edificios, parques y calles (Figura 2). Como mencioné, el proceso de transformación en la fisonomía de la ciudad había comenzado a partir del paso del turismo con rumbo al puerto, y se había incrementado en los años 50. Esto se ve reflejado en las imágenes donde se observa una composición mixta de viviendas y edificios hechos de bajareque y teja conviviendo con construcciones de cemento y loza, en el centro de la ciudad, que es donde transcurrieron las principales acciones. Asimismo, el piso sin concreto de una orilla de la calle permite ver las ampliaciones de la vialidad de ese período. 


\section{Revista Iberoamericana \\ de las Ciencias Sociales y \\ Humanísticas}

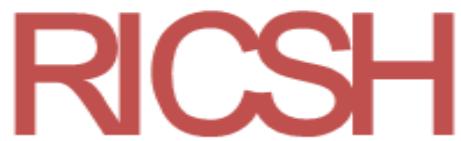

ISSN: $2395-7972$

Figura 2. Fotos cuyos detalles permiten observar el proceso de transformación urbano en

Chilpancingo durante el inicio de la segunda mitad del siglo XX

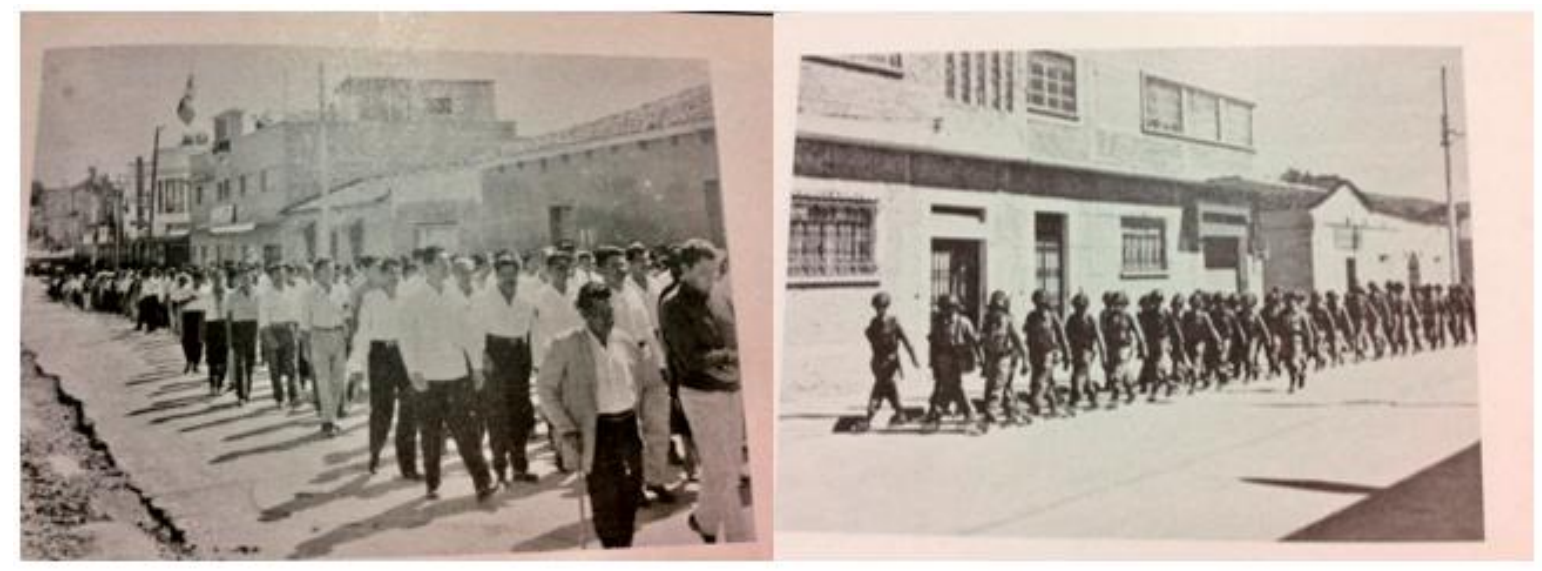

Fuente: Salmerón (1991, pp. 69 y 62, respectivamente)

\section{El estudio académico desde la fotohistoria: La familia Salmerón}

El primer estudio académico sobre fotografías de Guerrero es el texto de Blanca Jiménez y Samuel Villela publicado en 1998. En él, se aborda la producción fotográfica de tres generaciones de la familia Salmerón. Las diferencias de este libro con los demás reseñados, en cuanto a la documentación de las imágenes, son evidentes.

Mraz (2001) expone con mucho acierto que el libro se suscribe no solo a una historia gráfica, ya que nos muestra cómo incorporar la información que la fotografía contiene y ubicarla en el contexto histórico en que se produjo, sino que, además, su estudio se inscribe en la historia de la fotografía, ya que presentan las condiciones técnicas de su producción fotográfica y los medios a través de los que difundían su trabajo, elementos que hacen de este uno muy completo.

Jiménez y Villela (1998) mencionan que el primer fotógrafo de la familia Salmerón inició su trayectoria en la ciudad de Chilapa, donde abrió su estudio. Sin embargo, más adelante, algunos de sus descendientes se trasladaron a Chilpancingo, y en esa ciudad realizaron varios de sus trabajos más conocidos. Tal y como se ha visto en otros textos reseñados, las fotografías de Amando y Jesús Salmerón son referencias obligadas para quien se ha interesado en mostrar la imagen que la ciudad tenía en otras épocas. Y pese a que una buena parte de la producción fotográfica presentada en el libro son fotos de estudio, los fotógrafos mencionados, quienes eran muy versátiles y trabajaban también como 


\section{Revista Iberoamericana \\ de las Ciencias Sociales y Humanísticas}

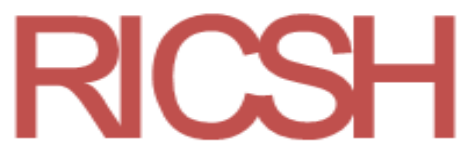

ISSN: $2395-7972$

fotoperiodistas, también registraron momentos y lugares de Chilpancingo en diversas ocasiones.

Dentro del texto hay varias vistas entre 1930 y 1940; de ellas, hay dos que llaman la atención para los fines aquí propuestos (Figura 3). La primera, registrada en 1940, de Amando Salmerón, es una panorámica aérea, de forma oblicua, que intenta abarcar la ciudad. En primer plano se observa la Alameda y las instalaciones de la universidad, ubicadas ambas a tres cuadras del centro hacia el norte; es decir, tomada de norte a sur. En total, siguiendo las avenidas que se visualizan con toda claridad, se pueden contabilizar cerca de las 10 cuadras que la ciudad alcanzaba en ese momento. Por el encuadre resulta un poco más complicado anotar lo mismo de oeste a este, aunque sabiendo que el límite poniente es el río, podemos presumir que el espacio que se visualiza en la imagen es la primera cuadra.

Figura 3. Foto 1: Panorámica de Chilpancingo, ca. 1940; foto 2: Cortejo fúnebre para los ahogados en el Balsas, en el paso de Mezcala. 4/XI/1930 ${ }^{8}$
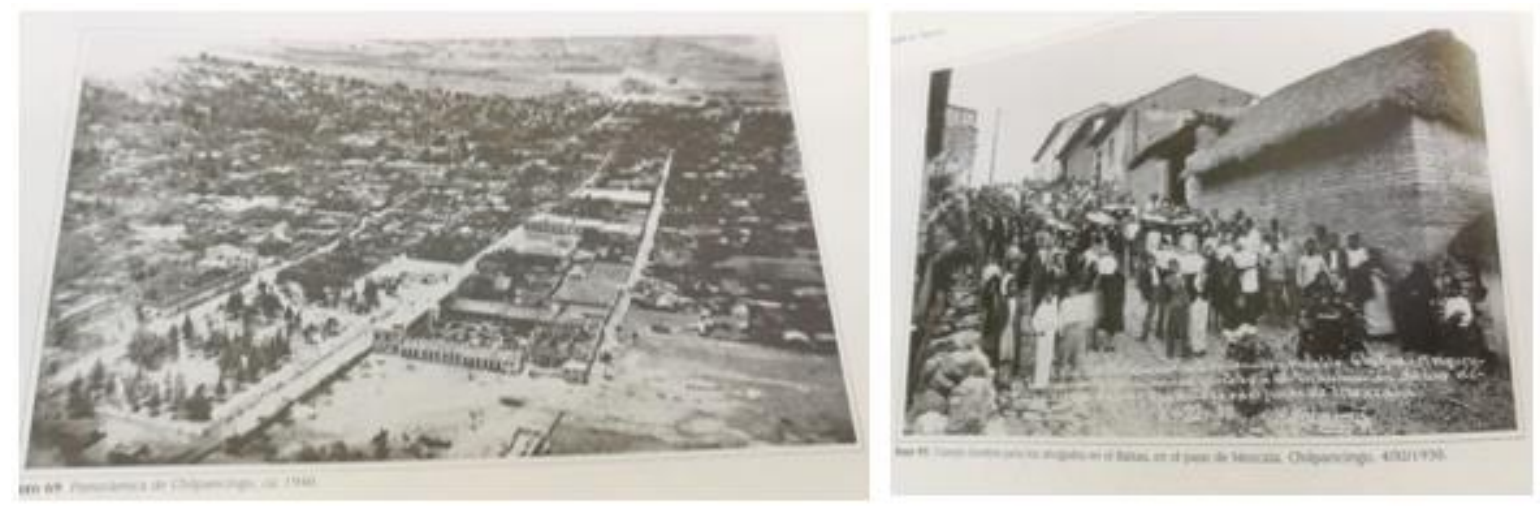

Fuente: Jiménez y Villela (1998)

La segunda imagen, también de Amando, esta de 1930, muestra un cortejo múltiple que baja por la calle Morelos con rumbo al panteón. Se visualizan cinco ataúdes y el pie de foto informa que se trata de personas que se ahogaron en el río Balsas. Lo que me interesa destacar es la casa que se encuentra en primer plano, ya muy cerca del río, con pared de adobe, al parecer, y el techo de palma. Estos materiales fueron habituales en otra época, incluso hay una crónica periodística del temblor de $1902^{9}$ que menciona que la iglesia tenía techo de palma a principios del siglo XX. No obstante, esa foto proporciona una imagen de

\footnotetext{
${ }^{8}$ Pies de foto en el libro.

${ }^{9}$ Nota publicada en el Sol de Chilpancingo el 18 de enero de 2003 en la columna Silueta del periodista que firma con el seudónimo Chansssonier.
} 


\section{Revista Iberoamericana \\ de las Ciencias Sociales y \\ Humanísticas}

ISSN: 2395 - 7972

un pueblo cercano a la costa, pues a Chilpancingo se le relaciona más con los techos de teja. Otra imagen tomada tres años después, sobre la visita del Niño Fidencio, muestra en otra localización la convivencia de ambos tipos de techumbre.

Varias de las imágenes expuestas en el libro ahora circulan ampliamente por la Red y en la comercialización informal de imágenes, proceso a través del cual, lamentablemente, se pierde la información de la fotografía. Afortunadamente ahí está el texto de Jiménez y Villela (1998) que documentó esas imágenes.

\section{Las publicaciones del gobierno de Cervantes Delgado: Chilpancingo ayer y hoy (1987) y dos folletos}

Durante el sexenio del gobernador Alejandro Cervantes Delgado (1981-1987), se publicó una serie de materiales sobre Chilpancingo que enfatizaba la historia y las acciones urbanísticas emprendidas por la administración en turno. La extensión, la morfología y la estructura de la ciudad había experimentado cambios drásticos a partir del gobierno de Rubén Figueroa Figueroa; con Alejandro Cervantes estos cambios se incrementaron aún más. ${ }^{10}$ Las medidas implementadas en ambos sexenios estaban relacionados con políticas urbanas a nivel federal. De hecho, muchas de las acciones implementadas se habían realizado con el financiamiento otorgado a través de proyectos federales.

En este contexto, los materiales impresos y videográficos que se publicaron desde el Gobierno estatal tenían el objetivo de difundir estos cambios. La publicación más importante del período es la monografía de Angélica Gutiérrez y Salgado, una recién egresada de la licenciatura en Historia de la Universidad Autónoma de Guerrero (UAGro), y que realizaba su investigación para titularse. Sabiéndose de este trabajo, puesto que Angélica laboraba en el Instituto Guerrerense de la Cultura, se le solicitó por parte de un colaborador cercano del gobernador trabajar el escrito con miras a una publicación, cuyas intenciones eran "darle sentido" a los datos geográficos e históricos que se tenían de Chilpancingo (p. 8).

\footnotetext{
${ }^{10}$ Integrante de la corriente de políticos tecnócratas del periodo de Miguel de la Madrid que le apostaban a la planeación pública, y nacido en Chilpancingo, se empeñó en cambiar la imagen de la ciudad y proyectar su desarrollo.
} 


\section{Revista Iberoamericana \\ de las Ciencias Sociales y \\ Humanísticas}

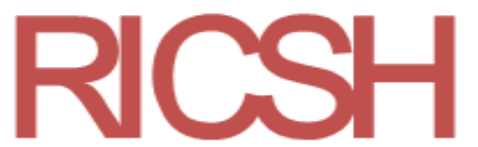

ISSN: 2395 - 7972

Para la publicación se contrató al fotógrafo Oliver Loaeza, quien hizo el registro de tomas recientes y también reprografió pinturas, dibujos y fotografías antiguas, entre las cuales se incluyeron fotos de Amando Salmerón, Jesús Salmerón, Guadalupe Damián y Raymundo Lujano.

El texto está organizado de manera cronológica. Las imágenes, por su parte, no siguen necesariamente esa secuencia; la lógica que siguieron tenía la intención de ilustrar los diferentes temas y relatos del libro. De tal suerte que tenemos algunas imágenes recientes ilustrando la exposición de hechos históricos, sin que se especifique que el lugar fotografiado no es el mencionado en el relato. Asimismo, hay algunas imprecisiones, como considerar fotografías a una serie de litografías de edificios públicos del siglo XIX que habían sido destruidos consecuencia de varios temblores; y asignarle la fecha de 1959 al edificio docente de la UAGro, pues este tuvo graves cuarteaduras en el sismo de 1957, por lo que fue demolido y construido uno nuevo.

Pese a estos errores, el valor testimonial del libro y de las imágenes de las que sí tenemos certeza, que son las registradas con miras a la publicación, es la de mostrarnos a la ciudad en un periodo de su historia. Acervo al que se le puede (y debe) seguir la pista. Lamentablemente, por razones de edición, a algunas fotografías en blanco y negro se les proporcionó tonalidades poco usuales: amarillo y azul, por lo que su lectura se complica un poco más.

Otros dos folletos amplían esta ventana hacia la ciudad de esa época (Dirección de actividades cívicas, sociales y culturales del estado 1981; Patronato de la feria 1986). Ambos tienen claramente la intención de ofrecer una comparación entre los años precedentes y los posteriores a las acciones urbanísticas del gobierno de Alejandro Cervantes. Y para hacerlo contrastan imágenes de algunos lugares capturadas en épocas distintas. Si bien todas las imágenes usadas fueron escasamente documentadas, constituyen una primera pista para buscar acervos de algunos de los autores mencionados o generar interés en recurrir a las imágenes como fuente de documentación de los cambios urbanos. 


\section{Revista Iberoamericana \\ de las Ciencias Sociales y \\ Humanísticas}

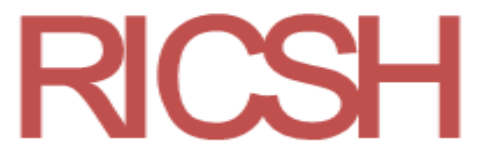

ISSN: 2395 - 7972

\section{Discusión}

Los estudios sociales e históricos que utilizan la fotografía como fuente documental en México son muy recientes, aunque ha habido un creciente interés en los últimos años. Las temáticas abordadas se inscriben principalmente en la fotohistoria, término acuñado por John Mraz (2007), y generalmente analizan la producción de algún fotógrafo o fotógrafa situándole en un contexto social y visual determinado, el estudio de algún hecho histórico donde la fotografía es el recurso metodológico principal o se analiza la imagen desde su cualidad estética. En este proyecto, se optó por analizar la representación visual de las ciudades guerrerenses combinando el estudio de la expansión urbana y el crecimiento de la infraestructura con su imagen. Lo anterior bajo la consideración de que hay una relación entre los hechos urbanos y arquitectónicos y el circuito de publicación de las imágenes, con el fin de difundirlas en distintos formatos, por motivos económicos, políticos, o artísticos y culturales.

Pese al impulso que ha tenido el uso metodológico de las imágenes en los estudios sociales, aún se trata de miembros de círculos pequeños quienes incorporan este acercamiento. ${ }^{11}$ En su texto sobre la filosofía de la fotografía, Vilém Flusser (1990) explica cómo las imágenes, en un inicio fundamentales para la humanidad en el registro y representación de la realidad, fueron relegadas por la escritura lineal. Este momento fue crucial para la comunicación humana, pero dio como resultado la sospecha de la imagen. A esta capacidad de abstraer formas planas para representar el espacio-tiempo exterior, el filósofo la llama imaginación (p. 11). Por su parte, la abstracción que se presenta en el texto escrito es una conceptualización. Pero esta sucede no como representación de lo real, sino como una mediación entre las personas y las imágenes que tienen de esa realidad (p. 14)

De esta forma, en la historia del discurso científico se muestra la absoluta dominación del texto escrito. Las imágenes, pese a cumplir una importante función de registro en disciplinas como la botánica o la antropología, son presentadas en la publicación de resultados para ilustrar, a manera de ejemplificación, de exposición gráfica, e incluso para

\footnotetext{
11 Los seminarios de fotografía del Instituto Nacional de Antropología e Historia (INAH) y la Mirada Documental del Instituto Mora, así como el Laboratorio Audiovisual de Investigación Social (LAIS) del Mora, y otros espacios audiovisuales en el Centro de Investigaciones y Estudios Superiores en Antropología Social (Ciesas) y la Escuela Nacional de Antropología e Historia (ENAH), son ejemplos de ello. Estas instancias de discusión y formación permiten poner en contacto a estudiosos de distintas latitudes, y conocer las nuevas temáticas que se abordan desde este campo de estudio.
} 


\section{Revista Iberoamericana \\ de las Ciencias Sociales y \\ Humanísticas}

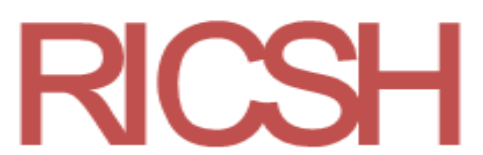

ISSN: $2395-7972$

hacer más atractivo el texto. El video Imágenes exitosas del investigador Fernando Aguayo, del Instituto Mora, proporciona varios ejemplos de ello; expone el papel secundario que se le asigna a lo visual al evidenciar el nulo reconocimiento del espacio y el tiempo de algunas imágenes que han sido reproducidas con frecuencia. De tal manera que una fotografía de trenes tomada a principios del siglo XX ilustra lo mismo textos sobre Cuba que sobre distintos lugares del país, y también son ubicadas con diferentes fechas. En ocasiones el desconocimiento sobre la imagen es aún más evidente, cuando se la coloca junto a textos que proporcionan información contradictoria a esta, como el ejemplo de un mapa del tranvía de Tacubaya en el video citado.

Esta situación es comprensible si se consideran las dificultades que implica su lectura. En su libro, Vilém Flusser (1990) ofrece una clave importante para comprender estos documentos. Puesto que las fotografías (imágenes técnicas) se construyen a partir de códigos culturales, "la 'condición cultural', puede informar sobre el acto fotográfico, y - como tesis - será posible descifrarlo a partir de las fotografías" (p. 33). Estos códigos culturales deben hacerse visibles.

Pero Flusser (1990) lleva su reflexión al aparato y el programa que contiene para la producción de esas imágenes. Entonces, plantea que existen tensiones entre las intenciones del fotógrafo y sus propios códigos culturales en la construcción de la imagen, y los programas de la cámara con los suyos propios. Todo aquel que emprenda un uso crítico de las imágenes debería poder distinguir en estas los códigos predominantes (p. 44). Y una segunda tensión tiene que ver con la fotografía y sus canales de distribución:

Los canales de distribución, los media, codifican el significado final de las fotografías. Esta codificación es el producto de la lucha entre el fotógrafo y los aparatos de distribución. Al ocultar esta lucha, el crítico normal de fotografía hace que los media en general sean invisibles para el receptor del mensaje fotográfico (Flusser, 1990, p. 50).

De esta manera, se podría decir que el análisis de las fotografías implica develar su historia a través de conocer los códigos de producción y de difusión, para que la información contenida en la imagen contribuya al estudio de la sociedad, y en este caso, al de las ciudades, desde su representación visual, así como los imaginarios que se generaron al ponerlas en circulación a través de distintos medios. 


\section{Revista Iberoamericana \\ de las Ciencias Sociales y \\ Humanísticas}

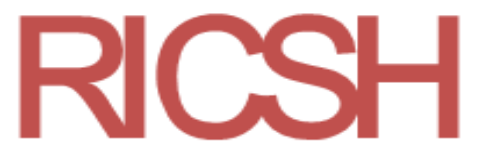

ISSN: $2395-7972$

\section{Conclusiones}

Hay una tendencia creciente en el del uso de la fotografía como un documento social y un mayor reconocimiento como discurso que debe ser analizado en un contexto social más amplio; esta tendencia se hace evidente en el incremento de publicaciones que la incorporan como una parte nuclear. No obstante, en el caso que se estudia, el tratamiento aún es muy desigual, pues no hay una debida identificación de estas, y en ocasiones ni siquiera hay un reconocimiento autoral. El único texto de los mencionados en el artículo es el publicado por el INAH, pues su finalidad es justamente reconocer la producción fotográfica de los guerrerenses.

La selección fotográfica en la mayoría de los textos reseñados, puesto que no tienen una investigación detrás, no posee una narrativa propia, autónoma, que se pueda entender solo si se miraran las imágenes. Tampoco hay correspondencia entre texto e imagen. A excepción, claro está, del libro de Francisco Tario y Lola Álvarez Bravo (1993), quienes hicieron el trabajo en conjunto, y el de Blanca Jiménez y Samuel Villela (1998).

En cuanto a la relación desarrollo urbano y las imágenes difundidas a través de este medio, sí se puede establecer alguna correspondencia entre uno y otro en los libros editados por el Gobierno, sobre todo si consideramos que se enmarcan en ese propósito. Las diferencias en el desarrollo urbano de ambas ciudades se objetivan en el hecho de que sus historias fotográficas son muy distintas. Mientras que en Chilpancingo las fotografías conocidas son producciones de fotógrafos locales fundamentalmente, con excepción de los casos en los que los fotógrafos fueron contratados expresamente para alguna publicación; en el puerto de Acapulco, en cambio, las imágenes existentes son mucho más abundantes y se trata de fotografías capturadas tanto por locales como por fotógrafos reconocidos en otras latitudes, debido principalmente al papel que este lugar tuvo como destino turístico mundial.

La intención de este trabajo fue contribuir al estudio social y urbano del estado de Guerrero, con la incorporación de la mirada fotográfica como una fuente más. Seguramente este primer esfuerzo es aún insuficiente, pues la producción fotográfica en Guerrero ofrece más posibilidades de estudio en esta perspectiva. A favor, se puede decir que la investigación aún no concluye, ya que se trabaja todavía en imágenes postales y de prensa que no forman parte de un grupo de imágenes incluidas en publicaciones actuales; para lo cual se rastrea en colecciones particulares, como la del historiador Francisco Montellano, la Fundación Héctor 


\section{Revista Iberoamericana \\ de las Ciencias Sociales y \\ Humanísticas}

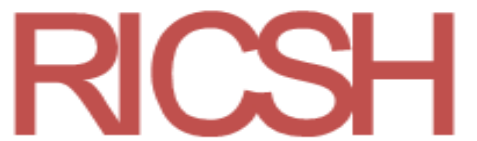

ISSN: $2395-7972$

García, la Galería López Quiroga, la familia Salmerón y algunas páginas de Facebook que incorporan fotografías de colecciones particulares de ambas ciudades.

\section{Referencias}

Aguayo, F. (2013) Imágenes exitosas. México: Instituto Mora.

Alcaraz, O. (2007). La arquitectura de los hoteles de Acapulco. 1927-1959. México: Universidad Autónoma de Guerrero.

Alcaraz, O. (2009). Evolución de la arquitectura hotelera en Acapulco. México: Universidad Autónoma de Guerrero / Conacyt.

Alessio, V. (1932). Acapulco en la historia y la leyenda. México: Mundial.

Babini, A., Alcaraz, O., Hernández, J. y Salgado, A. C. (2012). El deterioro urbano en las ciudades del Triángulo del Sol en Guerrero. En Rodríguez, M. A. y Rueda, R., Atlas de Guerrero (pp. 1-20). La Habana, Cuba: Instituto de Geografía Tropical de La Habana.

Besse, M. (2003). Geografías aéreas. En McLean, A., La fotografía del territorio (pp. 336363). Barcelona, España: Gustavo Gilli.

Burian, E. (1999). La arquitectura en instantáneas. Artes de México, (48), 44-51.

Canales, C. (1980). Romualdo García, un fotógrafo, una ciudad, una época. México: Gobierno del estado de Guanajuato.

Dirección de Actividades Cívicas, Sociales y Culturales del Estado. (1981). Síntesis histórica. México, Guerrero: Gobierno del estado de Guerrero.

Espinasa, J. (2000). Francisco Tario y el aforismo (algunas hipótesis). Revista Casa del Tiempo. Recuperado en http://www.uam.mx/difusion/revista/dic2000/index.html.

Ettinger, C. (2017). La arquitectura mexicana desde afuera: episodios en la construcción de un imaginario. México: Universidad Michoacana de San Nicolás de Hidalgo / Miguel Porrúa.

Fares del Río, R. (2011). Acapulco. Arquitectura y ciudad. México: Academia Nacional de Arquitectura.

Flusser, V. (1990) Hacia una filosofía de la fotografía. México: Trillas.

Garibay, R. (1978) Acapulco. México: Grijalbo.

González, L. (2010). Técnica e imagen. La fotografía de arquitectura como concepto. ArtCultura: Revista de Historia, Cultura e Arte, 12(21), 91-109.

\section{(c)}




\section{Revista Iberoamericana \\ de las Ciencias Sociales y \\ Humanísticas}

ISSN: $2395-7972$

Gutiérrez, A. y Rodríguez, H. (1987). Chilpancingo ayer y hoy (fotografía de Oliver Loaeza, Amando Salmerón, Jesús Salmerón, Guadalupe Damián y Raymundo Lujano). México: Instituto Guerrerense de la Cultura.

Hernández, E. (2017). Fotografía y género. Lola Álvarez en Acapulco. En Cárdenas, A., Saberes, memoria e imagen. Una construcción con enfoque de género. México: Ítaca / UAGro.

Illades, C. (1988). Textos básicos sobre el estado de Guerrero. Secuencia. Revista de Historia y Ciencias Sociales, (10), 57-75.

Jiménez, B. y Villela, S. (1998). Los Salmerón. Un siglo de fotografía en Guerrero. México: INAH.

Kossoy, B. (2014). Lo efímero y lo perpetuo en la imagen fotográfica. México: Cátedra.

Monroy, R. (2015). Nuevos retos para los fotohistoriadores: de la fotografía analógica a la digital. Iztapalapa. Revista de Ciencias Sociales y Humanidades, 36(78), 15-44.

Mraz, J. (2001). Historiar con imágenes. Estudios Interdisciplinarios de América Latina y el Caribe, 11(1), 77-92.

Mraz, J. (2007). ¿Fotohistoria o historia gráfica? El pasado mexicano en fotografía. Cuicuilco, 14(41),11-41

Patronato de la Feria. (1986). Chilpancingo ayer y hoy (fotografía de Jesús Salmerón y Juan Plata). México: Banamex.

Ramírez, J. (1987). Turismo y medio ambiente: el caso de Acapulco. Estudios Demográficos y Urbanos, 2(3), 479-512.

Salmerón, J. (1991). 1960. Historia gráfica de un movimiento social. México: Universidad Autónoma de Guerrero.

Tario, F. y Álvarez, L. (fotografía) (1993). Acapulco en el sueño. México: Televisa.

Valenzuela, E. y Coll, A. (2010) La construcción y evolución del espacio turístico de Acapulco (México). Anales de Geografía, 30(1), 163-190. 